\title{
ENTEROGENOUS CYST OF THE JEJUNUM: A RARE CASE REPORT
}

Khenpaw N. Lamare ${ }^{1}$, Chetan Maibam², L. Jaleshwar Singh ${ }^{3}$, S. Ranita Devi', T. Arun Kumar Singh ${ }^{5}$

\section{HOW TO CITE THIS ARTICLE:}

Khenpaw N. Lamare, Chetan Maibam, L. Jaleshwar Singh, S. Ranita Devi, T. Arun Kumar Singh. "Enterogenous Cyst of the Jejunum: A Rare Case Report". Journal of Evolution of Medical and Dental Sciences 2014; Vol. 3, Issue 39, August 28; Page: 9976-9978, DOI: 10.14260/jemds/2014/3294

CASE REPORT: A 5 years old male child was admitted in the Department of General Surgery, Regional Institute of Medical Sciences, Imphal, Manipur, with complaints of pain and a mass in the abdomen. On examination, abdomen was distended and a mass was felt which was cystic, non-tender, moved at right angle to the attachment of the mesentery and dull on percussion. USG and CECT Abdomen revealed a large cystic lesion in the right upper abdomen and pelvis displacing bowel loops suggestive of Omental/ Mesenteric cyst. Haematological, kidney, liver function tests and urine test were within normal limits. Exploratory laparotomy revealed a large multilobulated cystic mass in the jejunal mesentery around $15 \mathrm{~cm}$ from DJ junction. Grossly, the mass was $20 \times 20 \mathrm{~cm}^{2}$, containing 4 lobules, the largest lobule measures $8 \times 8 \mathrm{~cm}^{2}$ and weighs around $1 \mathrm{~kg}$. Three of the lobules were yellowish in colour and one was hemorrhagic. Excision of the cyst with $15 \mathrm{~cm}$ of the adjacent jejunum was done. A final diagnosis of Enterogenous cyst was made based on histopathological examination, which showed cyst wall containing smooth muscles as well as fibro connective tissues with lymphocytes in the subserosal areas with normal small intestinal mucosal tissue. Postoperative recovery was uneventful.

KEYWORDS: Mesenteric cyst, intraabdominal tumors, jejunal, Enterogenous cyst, Duplication cyst.

INTRODUCTION: Enterogenous cyst or Duplication cysts of the intestinal tract are rare congenital anomalies which may occur in any part from esophagus to anus, on the mesenteric side. Enterogenous cyst is a variant of Mesenteric cyst. Other terms used to describe this condition are enteric cyst, enterocystoma, ileum or jejunal duplex, unusual Meckel's diverticulum, giant diverticulum, etc.(1) Enterogenous cysts are most commonly found in the ileum and ileo-caecal region, least common in the rectum.

Approximately $75 \%$ of the cases are discovered in the first 2 years of life.(2) It presents either with chronic abdominal distension or acute with bowel obstruction or signs of peritonitis. Clinical presentation is varied or may be misleading due to a lack of awareness of clinical condition. (3)

Diagnosis is usually made during surgery. Histopathological examination is diagnostic.

DISCUSSION: Alimentary tract duplications are rare congenital malformations, which in most of the cases are diagnosed in infancy and childhood, although they can remain undetected until older age (4). The reported incident ranges from 1/20, 000 to 1/2, 50, 000 admissions in hospital.(5) Duplication cysts are composed of all layers of the bowel wall, i.e. submucosa and muscularis propria with their accompanying neural plexi (6). Most frequently cysts are localized in small bowel mesentery (ileum in $60 \%$ ) and mesocolon (ascending colon in 40\%) and they can be cystic or tubular.(7)

Our patient presented with a cyst in the jejunum, which again is the rarest. In $10-20 \%$ of patients, enteric duplications are multiple and may be associated with high incidence of other anomalies like spinal malformation, intestinal malrotation or atresias, urinary tract anomalies and skeletal anomalies. ${ }^{(8)}$ 
Signs and symptoms may vary widely and many patients remain asymptomatic till the cyst cause serious complications such as intestinal obstruction, hemorrhage, perforation or compressing other organs. Those arising from ileum may be confused with appendicitis. They may also present as intussusception. Radiologic studies although suggestive are not diagnostic. $(9,10)$

Optimal treatment is removal by excising the cystic duplication with the adjacent bowel. This case is reported because of their rare occurrence and varied presentation. It is a separate entity from chylolymphatic mesenteric cyst.

Enterogenous cyst usually becomes symptomatic early in life and they should always be included in the differential diagnoses when evaluating abdominal conditions in paediatric age group. General awareness with high index of suspicion is needed to avoid complications. The results of surgical therapy are good and patients have excellent long term outcomes and quality of life.

\section{REFERENCES:}

1. Ladd W E. Duplications of the Alimentary Tract. South Med. J; 30:363, 1937.

2. McLanahan S, Stone HB. Surg., Gynec. \& Obst. 58, I027, 1934.

3. Otter MI, Marks CG, Cook MG. An unusual presentation of intestinal duplication with a literature review. Dig Dis Sci 1996; 41: 627-629.

4. Yokoyama J. Duplications of the alimentary canal. Nippon Rinsho 1994; Suppl 6: 408-410.

5. Kurtz MD, Heiman TM, Beck AR, Holt J. Mesenteric and retroperitoneal cysts. Ann Surg 1986; 203:109-12.

6. Perot de M, Bründel MA, Tötsch M, Mentha G, Morel P. Mesenteric cysts: Toward less confusion? Dig Surg 2000; 17: 323-8.

7. Stringer MD, Spitz L, Abel R, Kiely E, Drake DP, Agrawal M et al. Management of alimentary tract duplication in children. Br J Surg 1995; 82: 74-8.

8. Puligandla PS, Nguyen LT, St-Vil D, Flageole H, Bensoussan AL, Nguyen VH et al. Gastrointestinal duplications. J Pediatr Surg 2003; 38: 740-744.

9. Paige M, Ghahremani G, Brosnan J. Laminated radiopaque enteroliths: Diagnostic clues to intestinal pathology. Am J Gastroenterol 1987; 82: 432-7.

10. Zamir G, Gross E, Shmushkevich A, Bar-Ziv J, Durst A, Jurim O. Duodenal duplication cyst manifested by duodeno-jejunal intussusception and hyperbilirubinaemia. J Pediatr Surg 1999; 34: 1297-99.

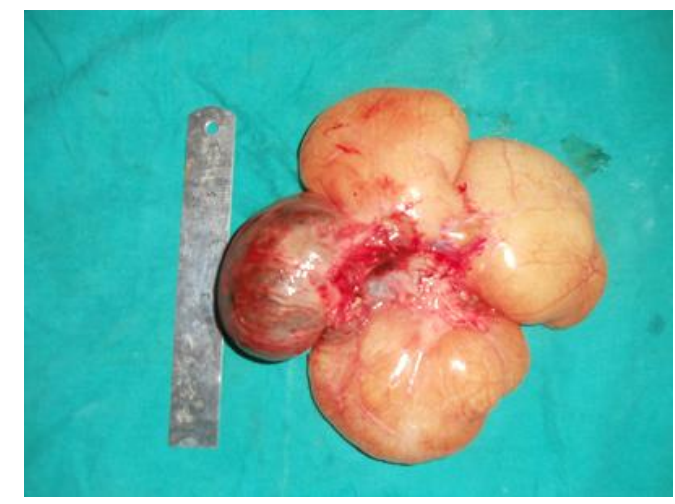

Excised Enterogenous cyst specimen 


\section{CASE REPORT}

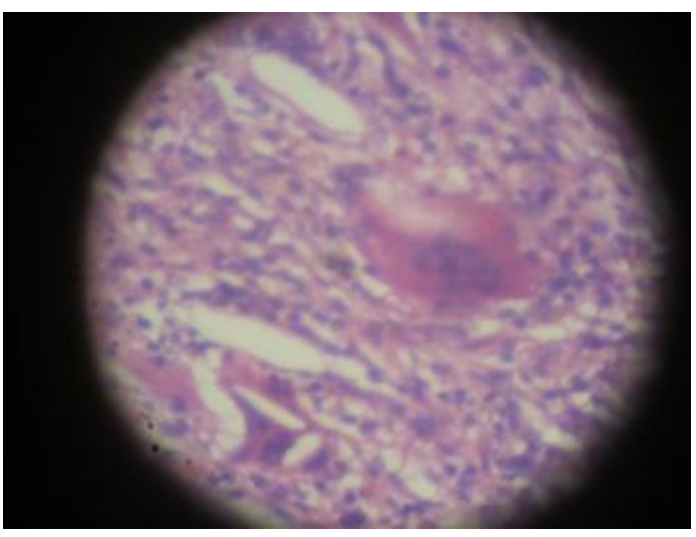

Histopathological picture of the Enterogenous cyst ( H\&E stain )

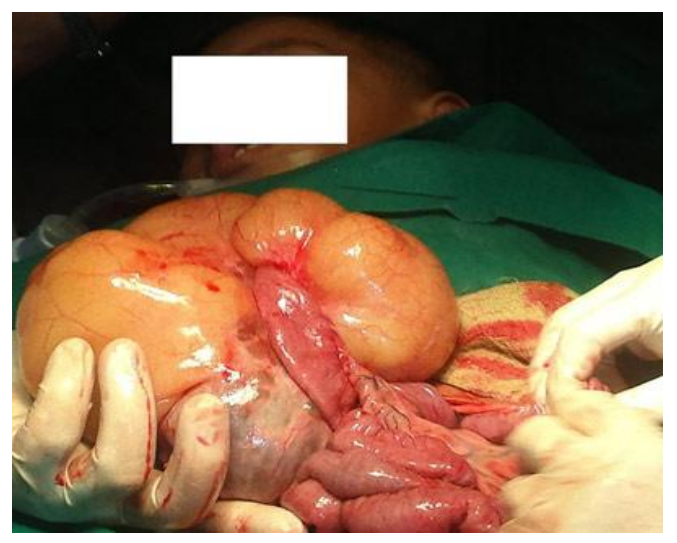

Intraoperative pic of the Enterogenous cyst.

\section{AUTHORS:}

1. Khenpaw N. Lamare

2. Chetan Maibam

3. L. Jaleshwar Singh

4. S. Ranita Devi

5. T. Arun Kumar Singh

\section{PARTICULARS OF CONTRIBUTORS:}

1. Post Graduate Trainee, Department General Surgery, Regional Institute of Medical Sciences, Imphal, Manipur.

2. Senior Registrar, Department General Surgery, Regional Institute of Medical Sciences, Imphal, Manipur.

3. Senior Registrar, Department General Surgery, Regional Institute of Medical Sciences, Imphal, Manipur.

4. Associate Professor, Department General Surgery, Regional Institute of Medical Sciences, Imphal, Manipur.
5. Professor, Department General Surgery, Regional Institute of Medical Sciences, Imphal, Manipur.

\section{NAME ADDRESS EMAIL ID OF THE CORRESPONDING AUTHOR:}

Dr. Khenpaw N. Lamare, PG Gents Hostel, Room 57, RIMS, Imphal, Manipur.

Email: knlamare@gmail.com

Date of Submission: 14/08/2014. Date of Peer Review: 15/08/2014. Date of Acceptance: 21/08/2014. Date of Publishing: 28/08/2014. 